\title{
Fake Publishing, Alternative Facts and Truthiness: Observations from a Conversation Café Held at CHLA/ABSC 2017
}

\author{
Janice Yu Chen Kung ${ }^{1}$, Maria C. Tan, and Sandy Campbell
}

\section{Introduction}

Issues of fake information are buffeting all libraries. In health libraries, where the quality of evidence is critical to the care of individuals, understanding the extent and nature of fake information and how to manage it is paramount. However, the area is volatile, the challenges change frequently, and librarian practices for managing fake information are in constant flux as everyone attempts to keep up. This session was designed to give health librarians an opportunity to spend an intensive hour discussing issues related to fake information, to learn about new developments in the field, and to network with colleagues.

\section{Methods}

Seventy-eight participants in the CHLA/ABSC 2017 Conference met in La Ronde Restaurant at the Chateau Lacombe in Edmonton, Alberta. Individuals were randomly distributed to 15 tables of 6 participants. One participant at each table was designated to record notes. Each table had copies of the same 5 questions and secondary prompt questions. Recorders prompted participants at their table to address the questions, and reported 1 prominent theme to the large group at the end of the session.
The authors of this abstract collated all of the notes by question. Each author independently reviewed 1 or 2 of the questions, identified prominent themes. The authors grouped comments under broad themes and came to consensus on the number of major themes to be reported.

\section{Results}

Nine prominent themes were identified across all 5 questions. These included: i) fake publishing as a growing problem; ii) fake publishing being more prominent in academic libraries, while fake "cures" or quackery are more prominent in hospital libraries; iii) libraries and librarians being viewed as trusted sources; iv) teaching critical appraisal and evaluation of resources having always been a part of information literacy; v) early career researchers being more at risk of falling prey to fake publishers and fake conferences; vi) researchers confusing "open access" with "predatory publishing"; vii) librarians looking for support from many resources; viii) no single tool available that is foolproof; ix) and a listing of many different tools and techniques for identifying fake information.

Janice Yu Chen Kung, Public Services Librarian, John W. Scott Health Sciences Library, Walter C. Mackenzie Health

Sciences Centre, University of Alberta, Edmonton AB

Maria C. Tan, Public Services Librarian, John W. Scott Health Sciences Library, Walter C. Mackenzie Health Sciences

Centre, University of Alberta, Edmonton AB

Sandy Campbell, Public Services Librarian, John W. Scott Health Sciences Library, Walter C. Mackenzie Health

Sciences Centre, University of Alberta, Edmonton AB

${ }^{1}$ Corresponding author (email: janice.kung@ualberta.ca)

(c) Kung, Tan, and Campbell.

This article is distributed under a Creative Commons Attribution License: https://creativecommons.org/licenses/by/4.0/ 


\section{Observations}

1. Fake publishing is a growing problem/ business manifesting itself as fake journals (inviting papers, reviewers and editors to add validity to the fake journal), fake conferences, fake impact assessment services and fake news. Health librarians have seen an increase in work related to fake information. Some participants reported being approached frequently to determine if a journal is real or fake. Participants reported that researchers who are aware of the fake journal/conference phenomena are "suspicious," "wary," "sceptical," "afraid," and "not confident" in determining whether or not they should publish in a particular journal or edit or review for it. Librarians have the skills to offer validation of good journals and reassurance for the researchers.

2. There are more fake journal and conference questions coming to academic health libraries than to hospital libraries. Activity in hospital libraries centres more around quack treatments and patients reading fake medical news.

3. Libraries/librarians are viewed as "authoritative" or "trusted" sources. While librarians certainly have the skill to determine whether or not a title or conference is fake, the simple existence of a title in a library's collection, which some people use as a standard, is not necessarily a mark of legitimacy. For example, many academic libraries rely on aggregator journal and e-book packages, which include publications that the library has not selected. In some aggregator packages, there is limited ability to suppress access to content that does not meet the library's criteria for selection. Even in librarianselected collections, fake journals and books may creep in.

4. In health libraries, teaching evaluation/critical appraisal has always been a part of information literacy and is currently a responsibility. However, the problem has become more prominent because the fake publishers market aggressively and are becoming more sophisticated and hence harder to identify.

a. While participants agreed that teaching critical appraisal skills is part of the role of health librarians, there was disagreement about the extent to which librarians should be involved in investigating the legitimacy of journals, conferences, and news. Some participants thought that while it is "our job to train people to assess and evaluate information critically," librarians "are not responsible for doing the critical thinking for end users." Other participants argued that librarians have unique skill sets that allow them to undertake these investigations efficiently and effectively. However, not all libraries are sufficiently well-staffed that librarians have time to take on extensive investigations.

b. Critical appraisal of information is fundamental to health education. Many librarians are incorporating the existence of and identification of fake sources into curriculum based information literacy programs. Several academic libraries have produced library guides dedicated to tips and techniques for identifying fake news, fake journals and fake information.

5. Fake journals and fake conferences only exist because of the "publish or perish" imperative of academia. Graduate students and junior faculty are most at risk because, as newcomers, they have more difficulty getting their work published and may not have the experience to identify fake venues. Some participants are targeting instruction about fake information to early career researchers.

6. Many participants reported a high level of confusion among their users, about open access (OA) and predatory publications. "There were misconceptions that all OA publications are predatory, and [researchers] were afraid to publish with open access because they did not know how to identify if a publisher was predatory or not." Meanwhile granting agencies require researchers to publish in open access publications.

7. A number of participants expressed a desire for support from among their colleagues or networks. Several either had access to, or wished for, a "Scholarly Publishing Office/Librarian" to take care of these challenges. Similarly, some participants thought there was a role for CHLA/ABSC in helping them to cope with fake information. The role of CHLA/ABSC was expressed as both making information available (e.g., checklists) and in offering continuing education around this subject.

8. Participants reiterated that while there are many trusted resources, nothing is foolproof. Participants cited predatory journals being listed in the Directory of Open Access Journals (DOAJ) and SCOPUS, as well as articles published in a predatory journal being indexed in PubMed although the journal was not. Google Scholar searches may also retrieve publications from predatory journals. In contrast, small, new, high quality journals often have difficulty being indexed until they have become wellestablished. "Quite a few significant Canadian journals 
are not in Medline, so checking for indexing is only one step." Libraries can point to resources, but the user still has to apply their judgment to the journal.

9. Participants used a number of tools and techniques for identifying fake information sources. The resources included: Publons, Quackwatch.org, Beall's List, SNOPES.com, Think.Check.Submit., Retraction Watch, Scholarly Kitchen blog, CARL primer and How to Assess a Journal infographic, and the CRAP Test.

Participants reported applying a variety of techniques for identifying fakes. Most obviously, librarians check the journal or conference website. Indicators include: domain names from unusual sources or that are incongruous with the content, poor quality of the site (e.g., spelling mistakes, poor grammar, poor quality images and multiple colours and sizes of font), vague information or unlikely names in the "About Us" section, lack of an authoritative source or editorial board, quality of previously published articles and authors of previous articles, peer review and publication policies, and contact information. Other red flags include: very fast turnaround for publication, relatively low pricing for publication or tiered pricing for fast turnaround, and requirements that payment be sent to an address in a country other than that of the journal or conference office mailing address.

Participants also reported checking to see that journals are indexed in a major index (e.g., MEDLINE) and also to determine whether or not they are indexed where they claim to be indexed. Participants contact editorial board members to ask about the quality of the journal. Sometimes the board members are not aware that they are listed as being affiliated with the journal. Participants also check the Internet Archive Wayback Machine to track the evolution of the website, and use Google Street View to view the physical location of the publisher or conference organizer's offices.

\section{Limitations}

The content of this abstract is restricted to the opinions of the participants who attended, filtered through the note-taking of the recorders. A different group of health librarians may have raised different issues. Some groups did not answer all of the questions because of the time limitation in the session. In collating the themes from the notes, the authors may have missed significant themes that were not frequently mentioned. Further, the brief nature of an extended abstract requires that much detail be excluded.

\section{Conclusions}

Fake information is perceived by librarians and health practitioners as a growing problem in which there is uncertainty. The large number of participants in this session is an indication of professional interest in this subject. Librarians and libraries are viewed by practitioners and researchers as trusted and authoritative sources of information to address these concerns. The uncertainty, fluidity and frequency of change in fake information, challenges librarians to constantly build awareness and expertise to meet users' needs and librarians are looking for support in this. This session indicates a need for more continuing education in this area and that a more thorough study of these issues is warranted.

\section{Acknowledgements}

The authors wish to acknowledge the contributions of the session recorders and participants.

\section{Statement of Competing Interests}

No competing interests declared. 